\title{
Influence of biofilm formation on the optical properties of novel bioactive glass-containing composites
}

\author{
Hong-Keun Hyun ${ }^{a, *}$, Jack L. Ferracane ${ }^{b}$ \\ a Department of Pediatric Dentistry, Dental Research Institute, School of Dentistry, Seoul National University, \\ Seoul National University Dental Hospital, 101 Daehakno, Jongno-gu, Seoul 03080, Republic of Korea \\ b Division of Biomaterials and Biomechanics, Department of Restorative Dentistry, School of Dentistry, \\ Oregon Health \& Science University, 2730 S.W. Moody Avenue, Portland, OR 97201, USA
}

\section{A R T I C L E I N F O}

\section{Article history:}

Received 17 December 2015

Received in revised form

7 March 2016

Accepted 22 June 2016

Keywords:

Bioactive glass

Dental composites

Biofilms

Color

\begin{abstract}
A B S T R A C T
Objective. Bioactive glass (BAG) has been suggested as a possible additive for dental restorative materials because of its antimicrobial effect and potential for promoting apatite formation in body fluids. The purpose of this study was to investigate the effects of bacterial biofilm on the change of colorimetric value and translucency of novel BAG-containing composites having different initial surface roughness.

Methods. Composites with $72 \mathrm{wt} \%$ total filler load were prepared by replacing $15 \%$ of the silanized Sr glass with BAG (65 mol \% Si; 4\% P; 31\% Ca), BAG-F (61\% Si; 31\% Ca; 4\% P; 3\% F; $1 \%$ B), or silanized silica. Light-cured discs of 2 -mm thickness ( $n=10 /$ group) were divided into 4 different surface roughness subgroups produced by wet polishing with 600 and then up to 1200,2400 , or 4000 grit SiC. CIE $L^{*} a^{*} b^{*}$ were measured and the color difference and translucency parameter (TP) were calculated before and after incubating in media with or without a Streptococcus mutans (UA 159) biofilm for $2 \mathrm{wks}$ (no agitation). Results were analyzed using ANOVA/Tukey's test $(\alpha=0.05)$.

Results. All the color differences for BAG and BAG-F composite showed significant decreases with bacterial biofilm compared to media-only. The mean TP (SD) of BAG and BAG-F composite before aging [10.0 (2.8) and 8.5 (1.4)] was higher than that of the control composite [4.9 (0.8)], while the change in TP with aging was greater compared to the control with or without bacteria. BAG-F composites with the smoothest surfaces showed a greater decrease in TP under bacterial biofilm compared to the BAG composite.

Significance. Highly polished dental composites containing bioactive glass additives may become slightly rougher and show reduced translucency when exposed to bacterial biofilms, but do not discolor any more than control composites that do not contain the BAG.
\end{abstract}

๔ 2016 The Academy of Dental Materials. Published by Elsevier Ltd. All rights reserved.

* Corresponding author. Tel.: +82 22072 0112; fax: +82 27443599.

E-mail addresses: hege1@snu.ac.kr (H.-K. Hyun), ferracan@ohsu.edu (J.L. Ferracane). http://dx.doi.org/10.1016/j.dental.2016.06.011

0109-5641/@ 2016 The Academy of Dental Materials. Published by Elsevier Ltd. All rights reserved. 


\section{Introduction}

New dental composites are being developed with bioactive additives having the potential to render them less susceptible to oral bacteria and promoting of tooth remineralization $[1,2]$. These composites will be used in all areas of the mouth, and will therefore have the same requirement for initial and long term esthetics as current materials.

Bioactive glasses (BAGs) area group of ceramic materials with the ability to bond chemically to both soft and hard tissues [3]. BAGs are considered a potential candidate as filler particles in resin-based dental composites, because they can enhance hard tissue regeneration and show some antimicrobial effect on oral microorganisms by the dissolution of the glass and releasing of ions in body fluids $[1,4,5]$. A recent study reported that BAG containing composites showed mechanical properties comparable to commercial composites [2]. Also, adding a filler particle based on a fluoride-containing BAG (BAG-F) enabled the composite to release both calcium and fluoride ions in solution, and to be rechargeable with fluoride upon exposure to external fluoride solutions [6]. While these properties provide optimism about the potential use of BAG additives in composites, the potential dissolution of the glass filler may cause concern about the integrity of the resin composite surface, and its overall esthetic appearance during aging.

The color of a resin composite is influenced by various factors including its light scattering and absorption characteristics, light reflectivity and translucency [7]. When light passes through a resin composite, it can be scattered in many different directions, primarily at the surface of the filler particles. Some of the light passes directly through as a more straight-line transmission while other light scatters through diffuse transmission, depending on the thickness of the composite [8-10]. The characteristics of the fillers and other additives used in the materials will therefore play a very significant role in determining their esthetic properties.

The characteristic of translucency allows an underlying background to show through by allowing light to at least partially pass through a material [11]. The inherent translucency of resin composites can be clinically beneficial for shade matching with an adjacent tooth by allowing the underlying and adjacent tooth structure to reflect or show through the restoration [12]. The translucency of tooth-colored restorative material is considered no less important than color, because the material with the same composite shade can look significantly different over different background colors [13]. A study reported that the translucency of resin composite was significantly correlated with diffuse light transmission, but not with the straight-line transmission [10]. It has been shown that the shape, size, and content of filler particles are all capable of affecting the light transmittance characteristics and color of resin composites [14].

Dental composites are susceptible to discoloration after prolonged exposure to the oral environment, and this is a function of their formulation [15]. One of the primary reasons dental composite restorations are replaced is due to unacceptable color change [16]. It is clinically important for these materials to maintain color stability for prolonged periods of time [17]. Therefore, conditions in which changes in color and translucency are produced within or on the surface during aging may cause the restoration to become clinically unacceptable. For example, it has been shown that organic acids and enzymes produced by bacteria within the oral biofilm can soften the resin matrix of dental composites [18], which can increase the susceptibility of the surface to staining $[19,20]$, and may therefore influence the overall esthetics of the restoration. However, little is known about the direct effect of bacterial biofilm formation on the stability of the optical properties of dental composites.

As new dental composite materials are produced with additives, such as BAG and calcium phosphates that may impart bioactive characteristics, it will be important to evaluate the color stability during aging, especially after exposure to clinically relevant oral conditions, such as biofilm formation. The aim of this study was to investigate the effect of bacterial biofilm on the optical properties of composites with different levels of polish, especially those containing potentially bioactive additives such as BAG and BAG-F. The hypothesis to be tested was that all composites would experience a change in color and translucency as a result of surface degradation, but that the BAG and BAG-F-containing composites would experience less change due to the presence of some antimicrobial effect. It was also expected that aging in media with or without bacterial would cause a dissolution of the BAG, creating a slight surface roughening, especially when the composite was highly polished. However, the effect of this roughening on the color change, if any, was not predictable and therefore important to assess.

\section{Materials and methods}

\subsection{Preparation of BAG}

BAG fillers were synthesized via sol-gel methods in our lab as previously described [1]. The synthetic glasses were ball milled in ethanol and sieved to a total particle size of less than $38 \mu \mathrm{m}$. The particles were then further processed using a Micronizer Jet Mill (Sturtevant Inc., Hanover, MA, USA), determined by laser particle size measurements (Beckman Coulter LS13 320, Brea, CA, USA) to routinely produce a fine particle size range $(0.04-3.0 \mu \mathrm{m})$.

\subsection{Formulation of experimental composites}

The three experimental composites all contained $57 \mathrm{wt} \%$ of strontium glass filler treated with silane $(1-3 \mu \mathrm{m}$ average size, Bisco, Inc.), further modified as follows: The control group included a silane-treated aerosol-silica (OX-50), while micronized BAG (BAG65) and fluorine-containing micronized BAG (BAG61) replaced the silica in the groups designated as BAG and BAG-F (Table 1). The fillers were mixed with Bis-GMA and TEGDMA monomers in a 50:50 formulation 
Table 1 - Compositions of resin composites tested.

\begin{tabular}{lll} 
Group & \multicolumn{1}{c}{ Fillers } & \multicolumn{1}{c}{ Monomers } \\
\hline Control & $57 \mathrm{wt} \%$ SG, 15 wt\% OX-50 & $28 \mathrm{wt} \%$ combination of Bis-GMA and TEGDMA (50:50) with 0.4 wt\% CQ \\
BAG & $57 \mathrm{wt} \%$ SG, 15 wt\% BAG65 & photoinitiator, 0.8 wt\% EDMAB tertiary amine accelerator, and \\
BAG-F & $57 \mathrm{wt} \%$ SG, 15 wt\% BAG61 & $0.05 \mathrm{wt} \%$ BHT inhibitor.
\end{tabular}

SG, silane-treated strontium glass, SG-35SRG4000 (Bisco Inc., Schaumburg, IL, USA).

OX-50, silane-treated aerosol-silica (Evonik Degussa, Parsippany, NJ, USA).

BAG65, Si $65 \mathrm{~mol} \%$, P $4 \mathrm{~mol} \%$ and Ca $31 \mathrm{~mol} \%$.

BAG61, Si $61 \mathrm{~mol} \%$, P $4 \mathrm{~mol} \%$, Ca $31 \mathrm{~mol} \%$, B $1 \mathrm{~mol} \%$ and F $3 \mathrm{~mol} \%$.

Bis-GMA, bisphenol A glycidyl methacrylate (Esstech Inc., Essington, PA, USA)

TEGDMA, triethylene glycol dimethacrylate (Esstech Inc., Essington, PA, USA).

$\mathrm{CQ}$ camphoroquinone (Esstech Inc., Essington, PA, USA).

EDMAB, 4-dimethylaminobenzoic acid ethyl ether (Acros Organics, Geel, Belgium).

BHT, butylated hydroxytoluene (Sigma-Aldrich, St. Louis, MO, USA).

using a centrifugal mixing device (Speed-Mixer DAC 150 FVZ, Hauschild, Germany) for 2 min at $2400 \mathrm{rpm}$.

\subsection{Specimen preparation}

Forty disk-shaped specimens of each composite group (10 mm diameter by $2 \mathrm{~mm}$ thickness) were prepared in vinyl polysiloxane molds with both top and bottom surfaces pressed with microscope slides to extrude excess resin. Specimens were light-activated using a curing unit (Demi ${ }^{\mathrm{TM}}$, Kerr, Orange, CA, USA) for $40 \mathrm{~s}$ on each side at $520-580 \mathrm{~mW} / \mathrm{cm}^{2}$. Specimens were separated from the mold and any flash on the side edge was carefully removed. They were then aged dry for $24 \mathrm{~h}$. A holder was created to maintain firm hand pressure on the specimen while it was rotating under cooling water on a polishing wheel covered with silicon carbide paper (Struers Inc., Cleveland, OH, USA). Every group was divided into four polishing subgroups of twelve specimens each in order to produce four distinct ranges of surface roughness as previously described [21]; Subgroup P600 was polished only on 600-grit SiC paper; P1200 sequentially on 600- and 1200-grit; P2400 sequentially on 600-, 1200-, and 2400-grit; and $\mathrm{P} 4000$ sequentially on 600-, 1200-, 2400-, and 4000-grit. The baseline surface roughness $(\mathrm{Ra}, \mu \mathrm{m})$ was measured using a surface roughness tester (TR200, TIME Group, Pittsburgh, PA, USA) at four different positions by rotating 90 degrees clockwise between measurements with five cut-offs of $0.25 \mathrm{~mm}$ each for a total length measured of $1.25 \mathrm{~mm}$.

\subsection{Colorimetric evaluation}

Initial color for all specimens was measured by CIE values, $L^{*}$ (lightness), $a^{*}$ (red-green coordinate), and $b^{*}$ (yellow-blue coordinate) against a white background and a black background using a Chroma Meter (CR-221; Minolta, Osaka, Japan). The device has a 3-mm diameter measuring area and uses 45-degree circumferential illumination and a 0 -degree viewing angle geometry for measuring precise areas of surfaces. The color values for each background alone were as follows, based on three individual measurements: white background $\left(L^{*}=93.879 \pm 0.106, a^{*}=2.148 \pm 0.044\right.$, $\left.b^{*}=-5.757 \pm 0.173\right)$ and black background $\left(L^{*}=12.197 \pm 0.219\right.$, $\left.a^{*}=-0.010 \pm 0.084, \quad b^{*}=-1.075 \pm 0.077\right)$. Calibration of the chromameter was performed before each measuring session.

\subsection{Biofilm procedure}

Overnight cultures of Streptococcus mutans (strain UA159) grown in brain heart infusion (BHI) at $37^{\circ} \mathrm{C}$ in a $5 \% \mathrm{CO}_{2}$ incubator were measured for optical density at $600 \mathrm{~nm}\left(\mathrm{OD}_{600}\right)$ and then diluted to an $\mathrm{OD}_{600}$ of $0.4-0.6$. A 1:10 dilution of the stock solution in new BHI medium was then incubated for $3 \mathrm{~h}$ to obtain $\mathrm{OD}_{600}=0.3$, which we previously determined from calibration curves represents a bacterial concentration of $9 \times 10^{7} \mathrm{CFU} / \mathrm{mL}$. Culture media were prepared by adding $3 w t \%$ sterile sucrose (Fischer Science Education, Hanover Park, IL, USA) to trypticase soy broth $\left(\mathrm{BBL}^{\mathrm{TM}}\right.$ Trypticase $^{\mathrm{TM}}$ Soy Broth, BD diagnostics, MD, USA). Five specimens from each surface roughness group were randomly chosen for the biofilm exposure group and were inoculated with S. mutans. An additional five specimens were used for the group to be aged in media only. All specimens $(n=120)$ were sterilized in $70 \%$ ethyl alcohol in an ultrasonic bath for $15 \mathrm{~min}$ followed by $100 \%$ ethyl alcohol for $15 \mathrm{~min}$. The sample disks were placed in six well culture plates. For the S. mutans group, a subculture $(1: 100)$ of $S$. mutans was added to the culture media and $5 \mathrm{~mL}$ was placed in each well using a sterilized pipette. For the control group, only $5 \mathrm{~mL}$ of the culture media free of $\mathrm{S}$. mutans was placed in an individual well. All specimens were incubated with $5 \% \mathrm{CO}_{2}$ at $37^{\circ} \mathrm{C}$ for 14 days, with the culture media being removed every $24 \mathrm{~h}$ and replaced with $5 \mathrm{~mL}$ of fresh sterilized culture media using a sterilized pipette. On the 13th experimental day, the samples were examined for contamination by culturing in BBL $^{\mathrm{TM}}$ Trypticase ${ }^{\mathrm{TM}}$ Soy Agar with $5 \%$ Sheep Blood (BD diagnostics, Hunt Valley, MD, USA). The biofilms were then removed from the samples by gently wiping with Kimwipes ${ }^{\mathrm{TM}}$ (Kimberly-Clark, Dallas, TX, USA) and rinsing with sterile water.

\subsection{Post incubation color assessment}

$\mathrm{Ra}$, and colorimetric value measurements on both the white and black backgrounds, were repeated on the surfaces after biofilm removal, in the same way, as the baseline measurements. 


\subsection{Calculation of translucency and the color difference $\left(\Delta E_{a b}^{*}\right)$}

The translucency of composite materials before and after treatment is usually measured using the translucency parameter (TP) [22]. TP was obtained by calculating the color difference of the specimen over a black (B) and white background (W) according to the following formula:

$\mathrm{TP}=\left[\left(L_{\mathrm{W}}^{*}-L_{\mathrm{B}}^{*}\right)^{2}+\left(a_{\mathrm{W}}^{*}-a_{\mathrm{B}}^{*}\right)^{2}+\left(b_{\mathrm{W}}^{*}-b_{\mathrm{B}}^{*}\right)^{2}\right]^{1 / 2}$

If the material is absolutely opaque, the TP is zero. The higher the TP value, the more translucent is the composite material.

The total color difference $\left(\Delta E_{a b}^{*}\right)$ from baseline to posttreatment was calculated for each specimen as:

$\Delta E_{a b}^{*}=\left[\left(\Delta L^{*}\right)^{2}+\left(\Delta a^{*}\right)^{2}+\left(\Delta b^{*}\right)^{2}\right]^{1 / 2}$

Where $\Delta L^{*}=L_{f}^{*}-L_{I}^{*} ; \Delta a^{*}=a_{f}^{*}-a_{I}^{*} ; \Delta b^{*}=b_{f}^{*}-b_{i}^{*} . L_{I}^{*}, a_{I}^{*}, b_{i}^{*}$ are referred to as the initial color measurement and $L_{f}^{*}, a_{f}^{*}, b_{f}^{*}$ as the final color measurement.

\subsection{Statistical analysis}

Statistical comparisons of changes of $\Delta E_{a b}^{*}, R a$, and TP between pre- and post-treatment were performed among each polishing level of P600, P1200, P2400, and P4000 for all three materials. The normality of the studied parameters was tested using the Kolmogorov-Smirnov test. If all followed a normal distribution, the values $n$ each group were compared by paired t-test. Otherwise, Wilcoxon Signed Ranks Test was used. For within-group comparison, if the data fulfilled the assumptions of normality and homogeneity of variance (Levene's test), they were compared by ANOVA. According to the results of the Levene statistic, post hoc comparisons were conducted using Tukey's or Dunnett's T3. If the parameters were not normally distributed, they were analyzed using the Kruskal-Wallis test. All statistical analyses were performed at $\alpha=0.05$ using SPSS 21 (IBM Corp., Somers, NY, USA).

\section{Results}

The mean (SD) baseline surface roughness ( $\mathrm{Ra}, \mu \mathrm{m})$ of the control, BAG, and BAG-F containing composites measured for P600 was 0.467 (0.061), 0.464 (0.053), 0.467 (0.043), respectively; for P1200 was 0.275 (0.043), 0.277 (0.030), 0.276 (0.035), respectively; for P2400 was 0.093 (0.014), 0.091 (0.023), 0.095 (0.013), respectively; and for P4000 was 0.050 (0.012), 0.047 (0.015), 0.049 (0.012), respectively. There were no significant differences between the three different types of composites with the same polishing level before treatment.

The mean TP (SD), measured before aging, of the control, BAG, and BAG-F containing composites for P600 was 4.9 (0.2), 9.0 (2.3), 7.5 (1.2), respectively; for P1200 was 4.6 (0.4), 8.9 (1.9), 8.2 (1.0), respectively; for P2400 was 5.1 (0.7), 10.2 (3.4), 8.6 (1.0), respectively; and for P4000 was 5.2 (1.4), 12.2 (2.2), 9.9 (1.1), respectively.

Colorimetric changes from pre- to post-treatment are shown in Table 2. Overall, $\Delta E_{a b}^{*}$ for BAG showed a higher value than those in the control and BAG-F either in media or biofilm $(P<0.05) . \Delta L^{*}$ in the control showed a lower value than in BAG

Table 2 - Mean (standard deviation) of changes of CIE value between pre- and post-treatment in media-only and with biofilm for each group submitted to different polishing levels over white background $(n=5)$.

\begin{tabular}{|c|c|c|c|c|c|c|}
\hline \multirow[t]{2}{*}{ Difference: SiC } & \multicolumn{3}{|c|}{ Media-only } & \multicolumn{3}{|c|}{ Biofilm } \\
\hline & Control & BAG & BAG-F & Control & $\mathrm{BAG}$ & BAG-F \\
\hline \multicolumn{7}{|l|}{$\Delta E_{a b}^{*}$} \\
\hline P600 & $4.1(0.1) \mathrm{Bb}$ & $4.9(1.3) \mathrm{Ba}$ & 4.8 (1.3)Bab & $3.9(0.6) \mathrm{Bb}$ & $4.3(0.3) \mathrm{BCa}^{*}$ & $3.5(0.2) \mathrm{Cb}^{*}$ \\
\hline P1200 & $4.1(0.1) \mathrm{Bc}$ & 7.2 (1.6)Aa & $4.5(0.1) \mathrm{Bb}$ & $3.8(0.1) \mathrm{Bb}$ & $4.2(0.4) \mathrm{Ca}^{*}$ & $3.8(0.5) \mathrm{BCb}^{*}$ \\
\hline P2400 & $3.9(0.1) \mathrm{Bc}$ & 7.1 (1.0)Aa & $4.7(0.2) \mathrm{ABb}$ & $4.1(0.3) \mathrm{Bb}$ & $4.6(0.3) \mathrm{Ba}^{*}$ & $4.2(0.6) \mathrm{ABb}^{*}$ \\
\hline P4000 & $5.0(0.2) \mathrm{Ab}$ & $7.2(0.6) \mathrm{Aa}$ & $5.1(0.5) \mathrm{Ab}$ & 4.7 (0.1)Ab & $5.2(0.3) \mathrm{Aa}^{*}$ & $4.3(0.3) \mathrm{Ac}^{*}$ \\
\hline \multicolumn{7}{|l|}{$\Delta L^{*}$} \\
\hline P600 & $-0.8(0.3) \mathrm{Cb}$ & 2.7 (2.1)Ba & 3.1 (1.6)Aa & $-0.3(0.2) \mathrm{ABC}^{*}$ & $2.5(0.6) \mathrm{Aa}$ & $1.6(0.3) \mathrm{Bb}^{*}$ \\
\hline P1200 & $0.1(0.3) B c$ & 5.1 (1.9)Aa & $2.4(0.3) \mathrm{Ab}$ & $-0.4(0.2) \mathrm{Bb}^{*}$ & $2.2(0.6) \mathrm{Aa}^{*}$ & $2.0(0.6) \mathrm{ABa}^{*}$ \\
\hline P2400 & $-0.1(0.4) \mathrm{Bc}$ & 4.9 (1.1)Aa & $2.7(0.4) \mathrm{Ab}$ & $0.0(0.3) A c$ & 2.5 (0.7)Aa* & $2.0(0.4) \mathrm{Ab}^{*}$ \\
\hline P4000 & $0.4(0.2) \mathrm{Ab}$ & 4.2 (1.6)ABa & $2.8(0.7) \mathrm{Aa}$ & $-0.1(0.4) \mathrm{ABc}^{*}$ & $2.5(0.7) \mathrm{Aa}^{*}$ & $1.9(0.4) \mathrm{ABb}^{*}$ \\
\hline \multicolumn{7}{|l|}{$\Delta a^{*}$} \\
\hline P600 & $1.5(0.1) \mathrm{Ba}$ & $0.5(0.1) \mathrm{Bc}$ & $0.8(0.1) \mathrm{Bb}$ & $1.3(0.2) \mathrm{Ca}^{*}$ & $0.6(0.1) \mathrm{ABb}^{*}$ & $0.6(0.1) \mathrm{Bb}^{*}$ \\
\hline P1200 & $1.4(0.2) \mathrm{Ba}$ & $0.9(0.2) \mathrm{Ab}$ & $0.7(0.1) \mathrm{Bc}$ & $1.3(0.1) \mathrm{BCa}$ & $0.6(0.1) \mathrm{Bc}^{*}$ & $0.6(0.0) \mathrm{Bb}^{*}$ \\
\hline P2400 & $1.4(0.2) \mathrm{Ba}$ & $0.5(0.2) \mathrm{Bc}$ & $0.8(0.1) \mathrm{Bb}$ & $1.4(0.1) \mathrm{Ba}$ & $0.7(0.1) \mathrm{Ab}^{*}$ & $0.8(0.1) \mathrm{Ab}$ \\
\hline P4000 & 1.7 (0.1)Aa & $0.5(0.4) B c$ & $0.9(0.1) \mathrm{Ab}$ & $1.7(0.2) \mathrm{Aa}$ & $0.6(0.1) \mathrm{Bc}$ & $0.8(0.1) \mathrm{Ab}$ \\
\hline \multicolumn{7}{|l|}{$\Delta b^{*}$} \\
\hline P600 & $-3.8(0.2) \mathrm{Ab}$ & $-3.7(0.7) \mathrm{Aab}$ & $-3.4(0.2) \mathrm{Aa}$ & $-3.6(0.6) \mathrm{Ab}$ & $-3.5(0.3) \mathrm{Ab}$ & $-3.1(0.2) \mathrm{Aa}^{*}$ \\
\hline P1200 & $-3.9(0.5) \mathrm{Aa}$ & $-4.9(0.8) \mathrm{Bb}$ & $-3.7(0.1) \mathrm{Ba}$ & $-3.6(0.1) \mathrm{Ab}^{*}$ & $-3.4(0.2) \mathrm{Ab}^{*}$ & $-3.1(0.2) \mathrm{Aa}^{*}$ \\
\hline P2400 & $-3.7(0.4) \mathrm{Aa}$ & $-5.1(0.4) \mathrm{Bb}$ & $-3.8(0.1) \mathrm{Ba}$ & $-3.8(0.3) \mathrm{Aa}$ & $-3.7(0.5) \mathrm{Aa}^{*}$ & $-3.7(0.6) \mathrm{Ba}$ \\
\hline P4000 & $-4.6(0.6) \mathrm{Bab}$ & $-5.5(1.2) \mathrm{Bb}$ & $-4.2(0.4) \mathrm{Ca}$ & $-4.4(0.4) \mathrm{Bb}$ & $-4.4(0.5) \mathrm{Bb}^{*}$ & $-3.8(0.3) \mathrm{Ba}^{*}$ \\
\hline
\end{tabular}

Different letters indicate significant differences among groups. Uppercase letters compare within columns, and lowercase letters compare within rows. Asterisks after values in the Biofilm section indicate differences between Biofilm and Media-only. Mean (SD) of CIE $L^{*}, a^{*}$, and $b^{*}$ measured on a white background was $93.879(0.106), 2.148(0.044)$, and $-5.757(0.173)$, resp. 
Table 3 - Mean (standard deviation) of changes of Ra $(\mu \mathrm{m})$ and Translucency Parameter (TP) before and after treatments in media-only and with biofilm for each group submitted to different polishing levels $(n=5)$.

\begin{tabular}{|c|c|c|c|c|c|c|}
\hline \multirow[t]{2}{*}{ Difference: SiC } & \multicolumn{3}{|c|}{ Media-only } & \multicolumn{3}{|c|}{ Biofilm } \\
\hline & Control & BAG & BAG-F & Control & BAG & BAG-F \\
\hline \multicolumn{7}{|l|}{$\Delta \mathrm{Ra}(\mu \mathrm{m})$} \\
\hline P600 & $-0.041(0.054) \mathrm{Ba}$ & $-0.028(0.048) \mathrm{Ca}$ & $-0.018(0.040) \mathrm{Da}$ & $-0.097(0.038) \mathrm{Cb}^{*}$ & $-0.031(0.036) \mathrm{Ca}$ & $-0.052(0.037) \mathrm{Da}^{*}$ \\
\hline P1200 & $0.002(0.233) \mathrm{Ab}$ & $0.027(0.026) \mathrm{Ba}$ & $0.028(0.036) \mathrm{Ca}$ & $-0.037(0.034) \mathrm{Bb}^{*}$ & $-0.016(0.043) \mathrm{Cb}^{*}$ & $0.013(0.021) \mathrm{Ca}$ \\
\hline P2400 & $-0.002(0.011) \mathrm{Ab}$ & $0.073(0.020) \mathrm{Aa}$ & $0.068(0.008) \mathrm{Ba}$ & -0.009 (0.009)Ab* & $0.048(0.022) \mathrm{Ba}^{*}$ & $0.052(0.014) \mathrm{Ba}^{*}$ \\
\hline P4000 & $-0.001(0.015) \mathrm{Ab}$ & $0.086(0.013) \mathrm{Aa}$ & $0.081(0.014) \mathrm{Aa}$ & $-0.004(0.010) \mathrm{Ab}$ & $0.064(0.007) \mathrm{Aa}^{*}$ & $0.066(0.009) \mathrm{Aa}^{*}$ \\
\hline \multicolumn{7}{|l|}{$\Delta \mathrm{TP}$} \\
\hline P600 & $-0.9(0.2) \mathrm{Ca}$ & $-3.3(1.6) \mathrm{Ab}$ & $-1.0(0.2) \mathrm{Aa}$ & $-0.5(0.1) \mathrm{Aa}^{*}$ & $-1.1(0.9) \mathrm{Ab}^{*}$ & $-0.9(0.7) \mathrm{Ab}$ \\
\hline P1200 & $-0.5(0.2) \mathrm{Aa}$ & $-2.5(0.5) \mathrm{Ac}$ & $-1.5(0.1) \mathrm{Bb}$ & $-0.6(0.1) \mathrm{Aa}$ & $-2.6(1.2) \mathrm{Bc}$ & $-0.9(0.4) \mathrm{Ab}^{*}$ \\
\hline P2400 & $-0.7(0.3) \mathrm{Ba}$ & $-3.8(1.2) \mathrm{Ac}$ & $-1.3(0.2) \mathrm{ABb}$ & $-0.8(0.4) \mathrm{Aa}$ & -1.1 (1.3)Aa* & $-5.1(0.8) \mathrm{Bb}^{*}$ \\
\hline P4000 & $-0.7(0.4) \mathrm{BCa}$ & $-3.7(2.9) \mathrm{Ab}$ & $-1.8(0.9) \mathrm{ABb}$ & $-0.4(0.4) \mathrm{Aa}$ & $-2.5(0.8) \mathrm{Bb}$ & $-5.6(0.4) \mathrm{Bc}^{*}$ \\
\hline
\end{tabular}

Different letters indicate significant differences among groups. Uppercase letters compare within columns, and lowercase letters compare within rows. Asterisks indicate differences between inoculation with and without Streptococcus Mutans.

and BAG-F regardless of bacterial biofilm, while $\Delta a^{*}$ in the control showed a higher value than in BAG and BAG-F $(P<0.05) . \Delta b^{*}$ showed little significant difference among different groups irrespective of bacterial biofilm $(P>0.05)$.

There was little significant difference in $\Delta E_{a b}^{*}$ of the control group between the two different treatments of media-only and biofilm, while those of BAG and BAG-F showed significantly less change with bacterial biofilm compared to media-only $(P<0.05) . \Delta E_{a b}^{*}$ of BAG showed the highest value at P1200, $\mathrm{P} 2400$, and $\mathrm{P} 4000$ both in media-only and biofilm compared to those of the control and BAG-F, while the differences for the biofilm were not as great as for the media-only. The higher $\Delta L^{*}$ for BAG at P1200, P2400, and P4000 in media-only is mostly responsible for the higher $\Delta E_{a b}^{*}$ for BAG.

There was less change in TP of the control group than that of BAG and BAG-F at every polishing level either in media or in bacterial biofilm $(P<0.05)$, except at $P 600$ in media-only. Most of the TP of BAG-F showed less change compared to that of BAG, while the change in TP of BAG-F at P2400 and P4000 with biofilm was significantly higher than that of BAG and the control group $(P<0.05)$ (Table 3$)$.

\section{Discussion}

It has been shown that resin composites with different filler types displayed different color characteristics [23]. In this study, the resin composite containing BAG and BAG-F particles tended to be darker, and to have more red and yellow hue than the control composite containing only silanized silica, and this was true both before and after either treatment.

The optical properties of composites are determined by absorption and scattering of light from the surface, as well as from the interior [24]. The perceived color and translucency of particulate-filled dental composites are closely related to their light-scattering properties [25]. The reflection of light from a rough surface, termed diffuse reflection, is a function of the different angles at which the light waves travel after colliding with that surface [26]. If a surface reflects more light, transmission must be proportionally reduced [26], and the material appears less translucent. In our study, the translucency of each composite increased and CIE $L^{*}$ decreased with decreased initial surface roughness as expected, i.e. the smoother surface produced less diffuse reflectance and allowed more light transmission. The $L^{*}$ coordinate, i.e. luminosity [27], is inversely proportional to the polishing level [28]. The more highly polished the surface, the less diffuse reflection occurs, resulting in greater light transmission/translucency and, consequently, less luminosity [29].

Light scattering which is closely related with translucency is known to increase when the difference in refractive indices of the filler and the matrix increases [25,30]. In the present study, the pre-treatment TP of BAG and BAG-F composite was higher than that of the control composite. This can be explained by a consideration of the refractive indices of the components. The refractive index of a commercial BAG, Bioglass (45S5, US Biomaterials, Alachua, FL, USA), is known to be 1.54-1.56, which is higher than that of OX50 (1.46), but lower than that of strontium glass (1.81) [31]. The mean refractive index measured in a study for $50 \%$ bisGMA/50\% TEGDMA was 1.502, and that for silane coupling agent ( $\gamma$-methacryloxypropyl-trimethoxysilane) to be 1.430 [32]. Therefore, replacing some of the strontium glass with BAG, which has a relatively smaller difference in refractive index mismatch with the resin matrix, can contribute to elevating TP of the BAG composites compared to the control.

Discoloration of restorations can be caused by intrinsic or extrinsic factors [17]. The intrinsic factors for discoloration of resin-based materials involve the discoloration of the resin material itself, such as the chemical alteration of the resin matrix or degradation of the interface between the matrix and fillers [33]. The resin matrix composition, filler loading, size and nature of the particles also must be considered [34]. In our study, there was no silanization of the BAG filler surface. The BAG surface is purposely not treated to allow it to be slowly dissolved in a body fluid in order to release potentially beneficial ions. It has been shown that this process does not reduce the physical properties of the BAG or BAG-F composite during aging in media or bacteria for up to two months compared to the control composite [2]. However, the surface properties of the composite with BAG are likely affected due to the dissolution, especially in the face of a bacterial challenge which may represent an extrinsic factor that can alter the surface appearance. The acid produced by the bacteria might cause 
a superficial hydrolysis and degradation, possibly followed by a slight penetration and reaction of possible staining agents within the superficial layer of the composites [17]. However, BAG is also known to release calcium ions during dissolution, which can elevate $\mathrm{pH}$ of the interfacial solution and prevent the attachment and growth of microorganisms [31]. Fluoride ion released from BAG-F might also have an anti-bacterial effect. These factors may then influence the change of colorimetric values for the composites, making them dependent upon their filler composition.

The rougher surface of BAG and BAG-F composite that was produced by the dissolution of the fillers during aging in the aqueous media with or without bacteria, likely contributed to the reduced post-treatment translucency due to the increased diffuse reflection from the irregular surface. However, not only CIE $L^{*}$, but also the CIE $a^{*}$ and $b^{*}$ values, changed after the aging procedure in the present study. Further, the color change was significant for the control composite as well as the BAG-containing composites, despite the fact that there was no observable change in the surface roughness of the highly polished control composite during aging. The results for the different composites suggest that the discoloration after aging in this study was also influenced by intrinsic factors for discoloration, and not simply due to changes in surface characteristics.

A color difference $\left(\Delta E_{a b}^{*}\right)$ less than 2.7 has been stated to represent a $50 \%$ acceptability threshold, and has been considered to be clinically acceptable [35]. All color changes in this study exceeded this value and would therefore be considered to be clinically discernible. The color difference for each composite was mostly influenced by $\Delta b^{*}$, which was consistent with previous findings $[17,36]$. The color changes for BAG and BAG-F were less influenced by $\Delta a^{*}$ and more influenced by $\Delta L^{*}$ compared to the control. Again, this result implies that aging, either in media-only or with biofilm, caused a surface roughening, resulting in the loss of luminosity and an elevation of the post-treatment $L^{*}$ in BAG and BAG-F compared to the control. It is significant that only the control group showed little difference in $\Delta E_{a b}^{*}$ between the media-only and the biofilm, suggesting that $S$. mutans bacteria did not influence the color change of the control composite, and that the changes were more a function of the media itself. However, the $\Delta E_{a b}^{*}$ value for BAG in media-only was higher than that in the control or the BAG-F composite, while there were no differences between BAG-F and the control in biofilm. Also, all the color differences for BAG and BAG-F composite after treating with bacteria showed significantly lower values than those without bacteria, suggesting that the presence of the bacterial biofilm actually lessened the color change that can be attributed to the media itself. Potentially the surface of the composite, being covered by the biofilm, was less exposed to the actual media and therefore the diffusion of media elements into the surface to produce staining or other internal alterations that contributed to the color change. This point is discussed further below.

A study measuring TP change after accelerated aging with and without UV showed significant decreases in TP of the studied resin composites after aging [37]. Another study using several light-cured hybrid resin composites showed significant decreases of TP after storing for 1 week in distilled water at room temperature [38]. Aging by exposure to radiation up to $450 \mathrm{~kJ} / \mathrm{m}^{2}$ in an accelerated aging chamber generally caused decreases in TP for both microhybrid and microfilled resin composites [36]. Results of the present study showed that post-treatment TP in every composite decreased after 2 weeks media storage with or without bacteria, which is in agreement with the results of these earlier studies showing that the resin composites became more opaque with aging. On the other hand, BAG filler particles tend to be dissolved easily in any aqueous solution $[4,39]$, which can lead to the creation of gaps at the interface between filler and matrix, leaving air-filled voids. Considering air to have an index of 1.000 , the difference in refractive indices between the phases can increase. This might explain the reason TP of the BAG or BAG-F composite decreased compared to the control composite after storage in the media with and without bacteria.

Intraoral bacterial biofilm formation may be considered an extrinsic factor in the discoloration of dental composites, because of the negative effect of its acidic byproducts on the surface [17]. In our previous study, an analysis of the surface roughness ( $\mathrm{Ra}$ ) and imaging with SEM demonstrated that specimen surfaces of BAG and BAG-F composites treated with biofilm showed less voids and surface roughness at the same level of polishing compared to those in media-only [21]. This result may suggest that biofilm coverage may to some extent prevent the soluble filler and the resin matrix from being exposed directly to the media. It has been generally accepted that Ra above $0.2 \mu \mathrm{m}$, a threshold surface roughness for bacteria retention based on in vivo studies, resulted in a simultaneous increase in plaque accumulation [40]. In this study, two groups of specimens had Ra below the threshold of $0.2 \mu \mathrm{m}$, i.e. those polished to P2400 and P4000. A study investigating the effect of surface properties of resin composite on biofilm formation using an in vitro artificial mouth system showed that bacteria biofilm was observed by SEM at the level of the threshold $\mathrm{Ra}$, although the biofilm was not continuous and there were free spaces in between the attached bacteria areas on the surface [41]. This observation is consistent with the SEM observations in our previous study [21] with BAGcontaining composites. It is possible that the effect of ions leached from BAG and BAG-F filler on altering the structure of the bacterial biofilm is more discernible in a highly polished composite because a relatively greater area of filler is exposed to the media and bacteria. It is true that the biofilm that does form may still have a negative influence on the resin matrix in terms of color stability, but the adverse effect caused by the biofilm may actually be less than that of the media-only, as shown here.

The BAG-F filler particle used in the present study had a larger surface area than the BAG filler [6]. This increased surface area for a soluble particle enhances the dissolution rate of ions from the glass [42]. Further, the BAG-F glass in this study contained boron. It has been reported that the dissolution rate for boron containing glass is greater due to the greater ease of breaking the $\mathrm{B}-\mathrm{O}$ bonds, vs. the $\mathrm{Si}-\mathrm{O}$ bonds, in the glass network [43]. In our previous study, SEM imaging demonstrated that the surface of BAG-F composites showed more voids than that for the BAG-containing composites at the same polishing level and treatment conditions, providing further evidence for this enhanced glass degradation [21]. Again, one would expect 
this dissolution from the glass to be further enhanced by polishing to a high smoothness due to the greater exposure of the filler. In fact, the post-treatment TP of BAG-F with bacterial biofilm showed a significant lower value in P2400 and P4000 in the present study, likely due to the degradative effects of the bacterial acid on the more soluble fluoride containing glass in BAG-F vs. BAG composite. However, the reverse effect in Media-only where the change in TP was greater for the BAG composite vs. BAG-F is not readily explainable.

\section{Conclusions}

Within the limits of this in vitro study, we conclude that bacteria biofilm showed little influence on the change of color and translucency of the control composite at the same polishing level. All the color differences for BAG and BAG-F composite after treating with bacteria showed significantly lower values than those without bacteria, possibly due to some protection of the surface to the effects of the media by the biofilm itself. The translucency of BAG and BAG-F composites were shown to be higher than that of the control, likely due to the substitution of some of the strontium glass with BAG. The translucency for all composites decreased after treatment with or without bacteria, with BAG-F composite showing a greater decrease at the highest polishing level under bacterial biofilm compared to BAG composite, which may be caused by the expected enhanced dissolution properties of the BAG-F glass. This work showed that while composite discoloration is to be expected when the material is exposed to bacterial biofilms, the presence of bioactive glass additives does not enhance discoloration compared to a non-BAG containing control, even though there is a significant, but slight, roughening when the surface was highly polished.

\section{Acknowledgement}

This study was supported in part by NIH/NIDCR grant R01 DE021372. We thank Bisco, Inc. for providing the filler particles and Esstech for providing the resin monomers. This paper is dedicated in memory of Satin Salehi, a great scientist who had an integral role in this study, and whose sudden, unexpected passing has saddened us all.

\section{REFERENCES}

[1] Mitchell JC, Musanje L, Ferracane JL. Biomimetic dentin desensitizer based on nano-structured bioactive glass. Dent Mater 2011;27:386-93.

[2] Khvostenko D, Mitchell JC, Hilton TJ, Ferracane JL, Kruzic JJ. Mechanical performance of novel bioactive glass containing dental restorative composites. Dent Mater 2013;29:1139-48.

[3] Hench LL, Greenspan D. Interactions between bioactive glass and collagen: a review and new perspectives. J Aust Ceram Soc 2013;49:1-40.

[4] Hench LL. Bioceramics: from concept to clinic. J Am Ceram Soc 1991;74:1487-510.

[5] Salehi S, Davis HB, Ferracane JL, Mitchell JC. Sol-gel-derived bioactive glasses demonstrate antimicrobial effects on common oral bacteria. Am J Dent 2015;28:111-5.
[6] Davis HB, Gwinner F, Mitchell JC, Ferracane JL. Ion release from, and fluoride recharge of a composite with a fluoride-containing bioactive glass. Dent Mater 2014;30:1187-94.

[7] Ota M, Ando S, Endo H, Ogura Y, Miyazaki M, Hosoya Y Influence of refractive index on optical parameters of experimental resin composites. Acta Odontol Scand 2012;70:362-7.

[8] Lim YK, Lee YK, Lim BS, Rhee SH, Yang HC. Influence of filler distribution on the color parameters of experimental resin composites. Dent Mater 2008;24:67-73.

[9] Arimoto A, Nakajima M, Hosaka K, Nishimura K, Ikeda M, Foxton RM, et al. Translucency, opalescence and light transmission characteristics of light-cured resin composites. Dent Mater 2010;26:1090-7.

[10] Horie K, Nakajima M, Hosaka K, Kainose K, Tanaka A, Foxton RM, et al. Influences of composite-composite join on light transmission characteristics of layered resin composites. Dent Mater 2012;28:204-11.

[11] Johnston WM, Ma T, Kienle BH. Translucency parameter of colorants for maxillofacial prostheses. Int J Prosthodont 1995;8:79-86.

[12] Sidhu SK, Ikeda T, Omata Y, Fujita M, Sano H. Change of color and translucency by light curing in resin composites. Oper Dent 2006;31:598-603.

[13] Ryan EA, Tam LE, McComb D. Comparative translucency of esthetic composite resin restorative materials. J Can Dent Assoc 2010;76:a84.

[14] Arikawa H, Kanie T, Fujii K, Takahashi H, Ban S. Effect of filler properties in composite resins on light transmittance characteristics and color. Dent Mater J 2007;26:38-44.

[15] Uchida H, Vaidyanathan J, Viswanadhan T, Vaidyanathan TK. Color stability of dental composites as a function of shade. J Prosthet Dent 1998;79:372-7.

[16] Wilson NH, Burke FJ, Mjör IA. Reasons for placement and replacement of restorations of direct restorative materials by a selected group of practitioners in the United Kingdom. Quintessence Int 1997;28:245-8.

[17] Nasim I, Neelakantan P, Sujeer R, Subbarao CV. Color stability of microfilled, microhybrid and nanocomposite resins - an in vitro study. J Dent 2010;38(Suppl. 2):e137-42.

[18] Asmussen E. Softening of BISGMA-based polymers by ethanol and by organic acids of plaque. Scand J Dent Res 1984;92:257-61.

[19] Asmussen E, Hansen EK. Surface discoloration of restorative resins in relation to surface softening and oral hygiene. Scand J Dent Res 1986;94:174-7.

[20] Lee YK, Powers JM. Discoloration of dental resin composites after immersion in a series of organic and chemical solutions. J Biomed Mater Res B Appl Biomater 2005;73:361-7.

[21] Hyun HK, Salehi S, Ferracane JL. Biofilm formation affects surface properties of novel bioactive glass-containing composites. Dent Mater 2015;31:1599-608.

[22] Kaizer Mda R, Diesel PG, Mallmann A, Jacques LB. Ageing of silorane-based and methacrylate-based composite resins: effects on translucency. J Dent 2012;40(Suppl. 1):e64-71.

[23] Hosoya Y, Shiraishi T, Oshiro M, Ando S, Miyazaki M, García-Godoy F. Color characteristics of resin composites in different color modes and geometries. J Oral Sci 2009;51:123-30

[24] Fernandez-Oliveras A, Rubiño M, Pérez MM. Scattering and absorption properties of biomaterials for dental restorative applications. J Eur Opt Soc Rap Public 2013;8:13056.

[25] Lee YK. Influence of scattering/absorption characteristics on the color of resin composites. Dent Mater 2007;23:124-31.

[26] Villarroel M, Fahl N, De Sousa AM, De Oliveira Jr OB. Direct esthetic restorations based on translucency and opacity of composite resins. J Esthet Restor Dent 2011;23:73-87. 
[27] Samra AP, Pereira SK, Delgado LC, Borges CP. Color stability evaluation of aesthetic restorative materials. Braz Oral Res 2008;22:205-10.

[28] Peyton JH. Finishing and polishing techniques: direct composite resin restorations. Pract Proced Aesthet Dent 2004;16:293-8.

[29] Croll TP. Simulating irregular enamel surface texture in composite resin restorations. Quintessence Int 1988;19:311-2.

[30] Born M, Wolf E, editors. Principles of optics. 6th ed. Oxford, UK: Pergamon Press; 1980.

[31] Jones J, Clare A, editors. Bio-Glasses: an introduction, 15. West Sussex, UK: John Wiley \& Sons; 2012. p. 170.

[32] Emami N, Sjödahl M, Söderholm KJ. How filler properties, filler fraction, sample thickness and light source affect light attenuation in particulate filled resin composites. Dent Mater 2005;21:721-30.

[33] Um CM, Ruyter IE. Staining of resin-based veneering materials with coffee and tea. Quintessence Int 1991;22:377-86.

[34] Dietschi D, Campanile G, Holz J, Meyer JM. Comparison of the color stability of 10 new-generation composites - an in-vitro study. Dent Mater 1994;10:353-62.

[35] Paravina RD, Ghinea R, Herrera LJ, Bona AD, Igiel C, Linninger $\mathrm{M}$, et al. Color difference thresholds in dentistry. J Esthet Restor Dent 2015;27(Suppl. 1):S1-9.
[36] Paravina RD, Ontiveros JC, Powers JM. Accelerated aging effects on color and translucency of bleaching-shade composites. J Esthet Restor Dent 2004;16:117-26.

[37] Lee YK, Lu H, Powers JM. Changes in opalescence and fluorescence properties of resin composites after accelerated aging. Dent Mater 2006;22:653-60.

[38] Johnston WM, Reisbick MH. Color and translucency changes during and after curing of esthetic restorative materials. Dent Mater 1997;13:89-97.

[39] Ohtsuki C, Kushitani H, Kokubo T, Kotani S, Yamamuro T. Apatite formation on the surface of ceravital-type glass-ceramic in the body. J Biomed Mater Res 1991;25:1363-70.

[40] Bollen CM, Lambrechts P, Quirynen M. Comparison of surface roughness of oral hard materials to the threshold surface roughness for bacterial plaque retention: a review of the literature. Dent Mater 1997;13:258-69.

[41] Ono M, Nikaido T, Ikeda M, Imai S, Hanada N, Tagami J, et al. Surface properties of resin composite materials relative to biofilm formation. Dent Mater J 2007;26:613-22.

[42] Leuner C, Dressman J. Improving drug solubility for oral delivery using solid dispersions. Eur J Pharm Biopharm 2000;50:47-60.

[43] Liu X, Huang W, Fu H, Yao A, Wang D, Pan H, et al. Bioactive borosilicate glass scaffolds: in vitro degradation and bioactivity behaviors. Mater Sci Mater Med 2009;20:1237-43. 